\title{
Retrosigmoid Approach for Resecting a Giant Lateral Pontine Ependymoma: Two-Dimensional Operative Video
}

\author{
Hongxiang Wang, ${ }^{1, *}$ Yong Yan ${ }^{1, *}$ Tao $\mathrm{Xu}^{1}$ Juxiang $\mathrm{Chen}^{1}$ \\ ${ }^{1}$ Department of Neurosurgery, Changzheng Hospital, Naval Medical \\ University, Neurosurgical Institute of Shanghai, Neurosurgical \\ Institute of People's Liberation Army, Shanghai, China \\ Address for correspondence Juxiang Chen, MD, PhD, Department of \\ Neurosurgery, Changzheng Hospital, Naval Medical University, \\ Neurosurgical Institute of Shanghai, Neurosurgical Institute of \\ People's Liberation Army, 415 Fengyang Road, Shanghai 78316, China \\ J Neurol Surg B 2021;82(suppl S1):S53-S54. \\ (e-mail: juxiangchen@smmu.edu.cn).
}

\begin{abstract}
Ependymoma is one of the most common pediatric tumors in central nervous system, for which gross total resection has been the most favorable prognostic factor. ${ }^{1,2}$ However, surgery of ependymomas located in brain stem is significantly challenging. This video demonstrates the microsurgical removal of an ependymoma originating from ependymal cells of the lateral recess of fourth ventricle via retrosigmoid approach in an 11-year-old female. The patient presented with a 6-month history of continues headache and vomiting. On examination, she had a walking instability and an emaciated body. Neuroimaging revealed a right lateral pontine lesion extending to the cerebellopontine angle region. The patient underwent a suboccipital craniotomy, followed by excellent exposure for the tumor. Petrosal vein encased by the tumor mass and close adhesion of the tumor and the initial segments of facial and acoustic nerves adjoined brain stem could be seen operatively. While preserving trigeminal nerve, facial and acoustic nerves, posterior cranial nerves, anterior inferior cerebellar artery, labyrinth artery, posterior inferior cerebellar artery, and petrosal vein, gross total resection was achieved under the careful operation along arachnoid spaces together with intratumoral decompression. The patient tolerated the procedure well

\section{Keywords}

- operative video

- surgical video

- ependymoma

- lateral pontine tumor

- retrosigmoid approach

without any neurological deficits. Histological examination confirmed the tumor as an ependymoma (WHO II). The cytology measurement of the cerebrospinal fluid did not find any tumor cells. Postoperative computed tomography and magnetic resonance imaging scan depicted complete resection of the tumor, and adjuvant radiotherapy was recommended. She remained symptom-free without any evidence of recurrence during the follow-up period of 1 year. Informed consent was obtained from the patient. The link to the video can be found at: https://youtu.be/sZ9GhUeltwc.
\end{abstract}

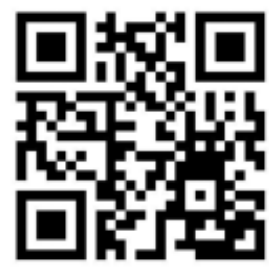

These authors contributed equally to this work.

received

September 2, 2019

accepted

January 5, 2020

published online

September 17, 2020
DOI https://doi.org/

10.1055/s-0040-1705158. ISSN 2193-6331.

\author{
Conflicts of Interest \\ None. \\ Disclosure of Funding \\ None. \\ www.thieme.com/skullbasevideos \\ www.thieme.com/jnlsbvideos
}

(c) 2020. The Author(s).

This is an open access article published by Thieme under the terms of the Creative Commons Attribution-NonDerivative-NonCommercial-License, permitting copying and reproduction so long as the original work is given appropriate credit. Contents may not be used for commercial purposes, or adapted, remixed, transformed or built upon. (https://creativecommons.org/ licenses/by-nc-nd/4.0/)

Georg Thieme Verlag KG, Rüdigerstraße 14, 70469 Stuttgart, Germany 

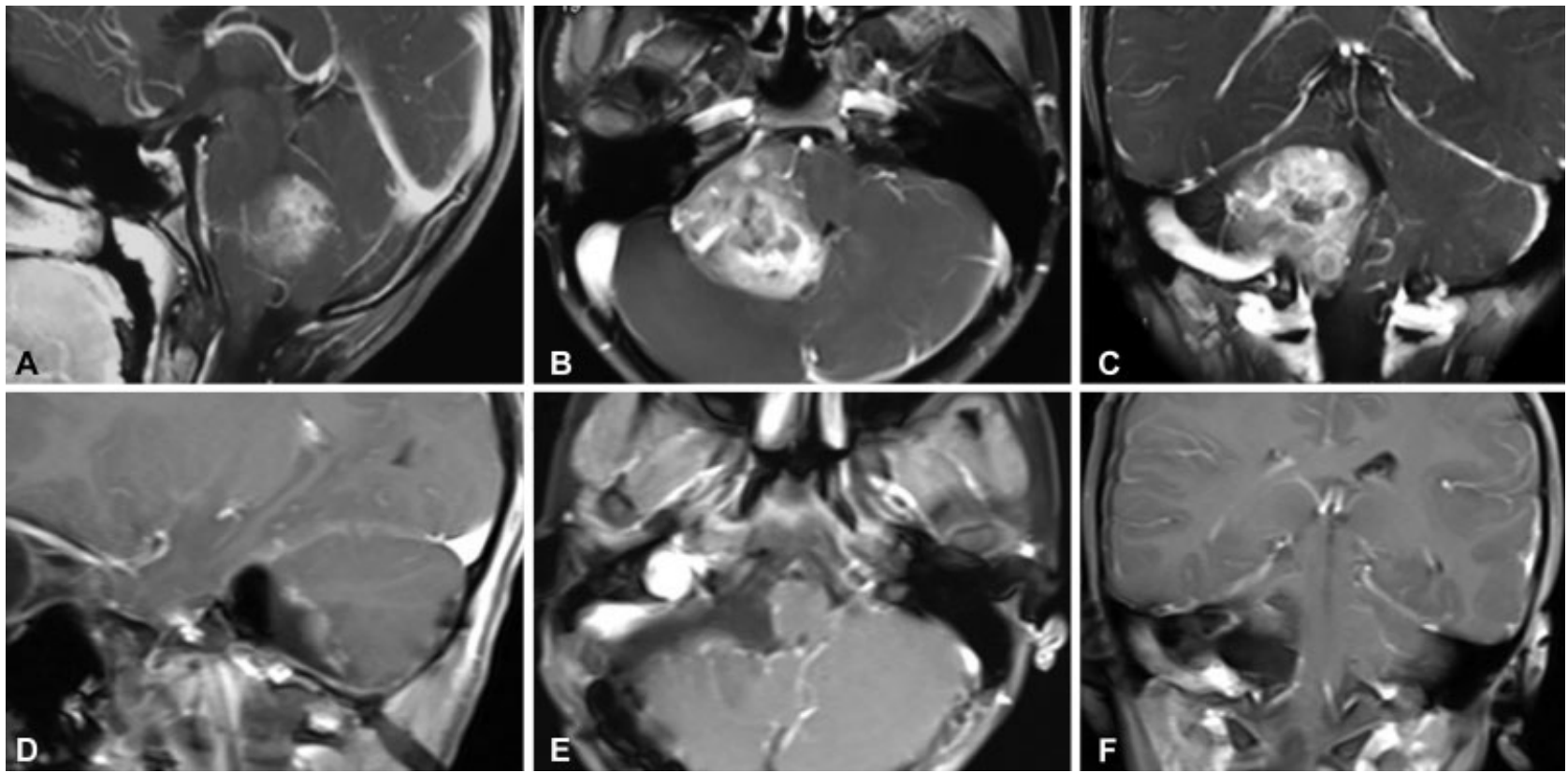

Fig. 1 Preoperative (A-C) and postoperative (D-F) MRI images of the lateral pontine ependymoma.

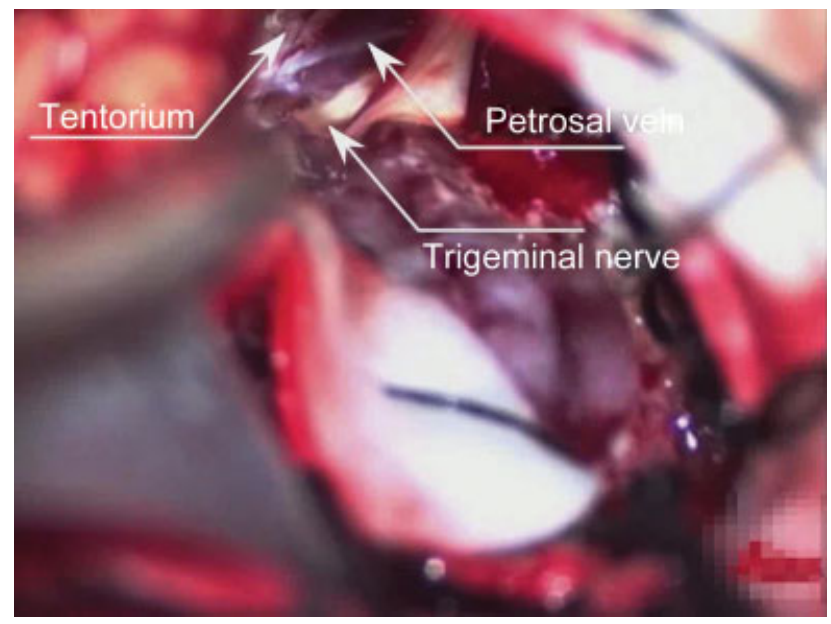

\section{References}

1 Khatua S, Ramaswamy V, Bouffet E. Current therapy and the evolving molecular landscape of paediatric ependymoma. Eur J Cancer 2017;70:34-41

2 Rudà R, Reifenberger G, Frappaz D, et al. EANO guidelines for the diagnosis and treatment of ependymal tumors. Neuro-oncol 2018;20(04):445-456

Fig. 2 Intraoperative image showes the exact position and adjacent structures of the tumor. 